\title{
Ultra-High-Performance Concrete-A Game Changer in Structural Engineering
}

\author{
Maher K Tadros* and David Gee \\ e.construct USA LLC, USA
}

*Corresponding author: Maher K Tadros, e.construct USA LLC, Omaha, Nebraska, USA.

\section{Introduction}

Ultra-high-performance concrete (UHPC) was first introduced as reactive powder concrete in the early 1990s by employees of the French contractor Bouygues. Since then, France, Japan, Malaysia, South Korea, and several other countries have made significant progress in using this material for bridge construction and other applications. The first roadway bridge with UHPC beams was built in France in 2001, and was comprised of five double-tees, with a beam section referred to as a " $\pi$-shape." In the United States, several state departments of transportation are exploring applications of UHPC for their bridge projects, with support from research conducted by the Federal Highway Administration (FHWA) and their local universities. Most notably, Virginia has produced I-beams with UHPC, and Iowa has built two bridges with UHPC beams and one with a UHPC deck in the past ten years. Several companies market prepackaged UHPC mixes in the United States. However, due to the high cost of these prebagged mixes, UHPC has been mostly limited to the demonstration projects in Virginia and Iowa, which were subsidized by the FHWA, or limited quantities in the joints between precast concrete members.

To Advance UHPC applications in the united states, two conditions need to be met:

1. The cost of UHPC raw materials must be reduced to less than $\$ 1,000$ per cubic yard, compared to a cost of approximately $\$ 2,500$ per cubic yard for prebagged materials, and

2. Structural systems must be developed to capitalize on the unique capabilities of UHPC and allow for reduction of member weight by about $50 \%$ while maintaining acceptable strength and stiffness and preserving the very high durability of the material. The Precast/Prestressed Concrete Institute (PCI) has recognized this need and decided to devote resources for the benefit of its precast producer members and the taxpayers of the US. As a result, the PCI awarded an implementation project that is led by e.construct, with participation from Wiss, Janney, Elstner Associates, the University of Nebraska-Lincoln, North Carolina State University, and the Ohio State University.

This ongoing PCI Project has completed its first phase with a comprehensive report expected to be published in the spring of 2020. Both goals of achieving cost-effective locally mixed and produced UHPC mixes and optimized structural members for buildings and bridges were successfully completed. When the project findings are implemented, it is expected that the UHPC products will be competitive based on initial cost. Several full-scale bridge and building elements have been produced and tested. The results have been outstanding. Most of the products failed at loads much higher than required in service. In addition, the material is like ceramic. It has nearly zero porosity and has a service life expectancy of several hundred years, as opposed to conventional concrete, which is designed for a 75-year service life. Phase II of the PCI project is ongoing. It includes full scale testing of components and full members. It is intended to verify, refine, and confirm the tentative design guidelines given in Phase I.

\section{What is Unique about UHPC?}

Figure 1 displays the primary constituents for UHPC mixtures. Currently, there is not a universally accepted definition of UHPC. Typically, the design compressive strength ranges from $17 \mathrm{ksi}$ to $22 \mathrm{ksi}$, which is nearly 5 times the compressive strength of conventional concrete (Figure 1).

Compressive strength is not the most important property. Tensile strength and tensile ductility are the keys to success with UHPC. The high tensile strength allows for significantly higher shear resistance, with the possibility of total elimination of the stirrups. When stirrups are eliminated, significant simplification of design 
and precast production results. Also, member web (stem) width is greatly reduced, which results in significant weight reduction. Figure 2 shows the great difference between tensile behavior of UHPC and that of conventional concrete (CC). For example, 4 ksi CC has a flexural tensile strength of about $0.450 \mathrm{ksi}$, while the corresponding UHPC value can be as high as ten times that value.
UHPC also deflects in the standard ASTM C1609 prism test an amount larger than span/150 without losing much of its strength. This behavior demonstrates tremendous toughness and ability to absorb energy even without the help from reinforcing bars (Figure 2).

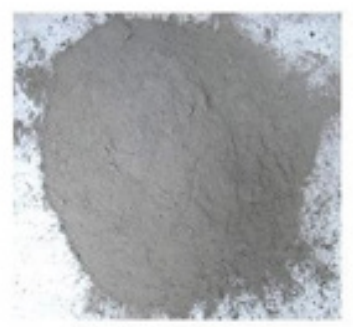

Portland Cement

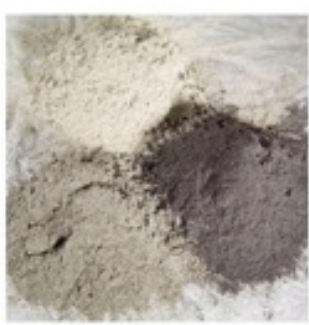

Supplementary Materials

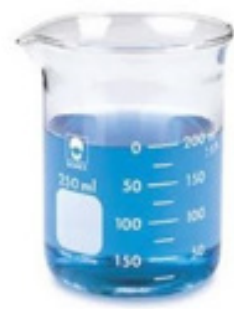

Superplasticizers

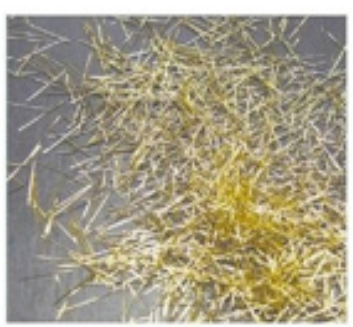

Fiber Reinforcement

Figure 1: Components of UHPC.

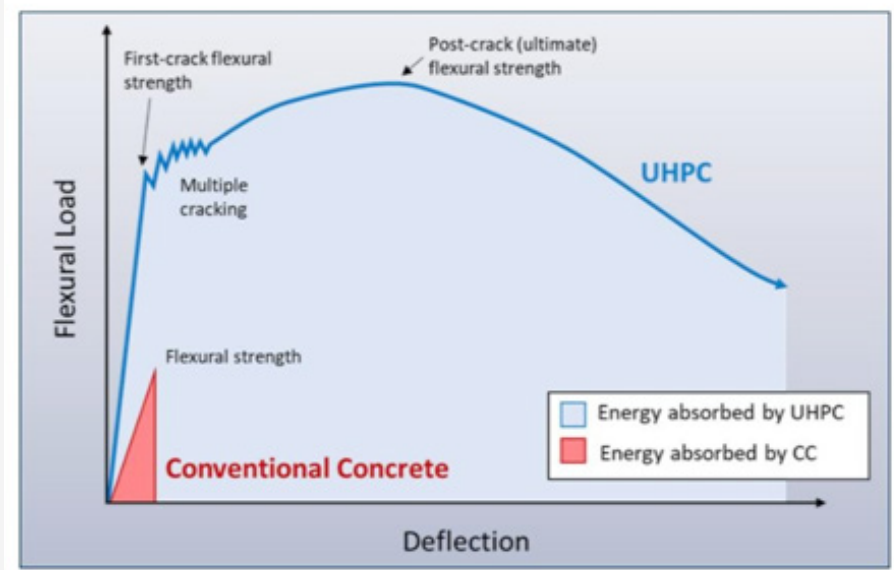

Figure 2: Comparison of UHPC and Conventional Concrete (CC) Under Flexural Loading.

\section{Example Applications of UHPC}

Figure 3 shows a design concept for use in buildings. The voided slab is a two-piece precast, prestressed floor that allows for a 60 - $\mathrm{ft}$ span using a depth of 22 inches. No steel, other than the prestressing strands, is needed for this design. The top flange is only one inch thick and the stems are only two inches wide. The stems have openings to allow for integration of utilities. The overall weight corresponds to a solid slab less than 4 inches thick. With this product, residential multistory buildings can have column-free parking in the lower floors, which enhances safety of the residents (Figure 3).

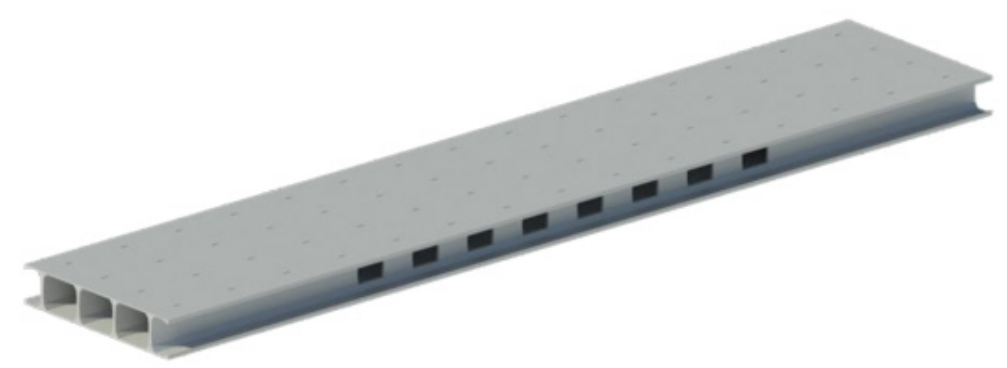

Figure 3: Concept of a UHPC Voided Slab System for Residential applications. 
Figure 4 shows an isometric view of an optimized decked I beam to be used in accelerated bridge construction (ABC) applications. It has a 4 inch wide web and a ribbed (waffle) slab top flange with a top skin of only 2-3 in. and rib depth of $8 \mathrm{in}$. As a result, the product has about 50 percent of the concrete and less than 30 percent of the reinforcing bars, compared with conventional concrete. Not having rebar for stirrups in the webs greatly simplifies design and precast production (Figure 4).

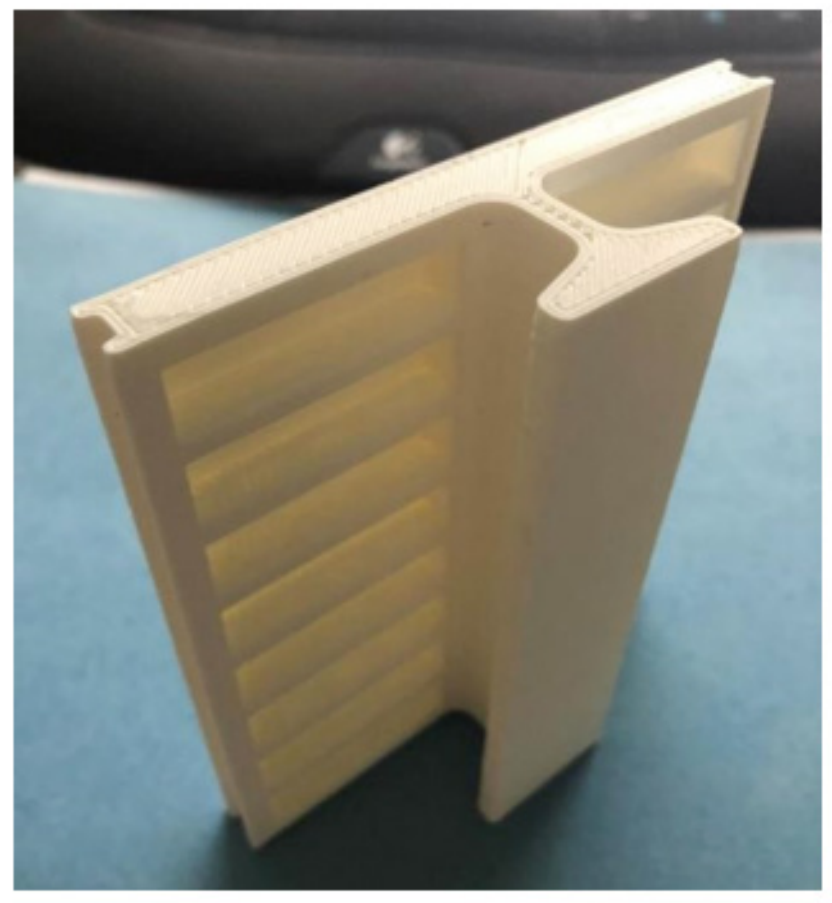

Figure 4: 3-D Print of Concept of a UHPC decked I-beam for bridge applications.

\section{The Future}

The information presented in this article shows that UHPC has an excellent potential to replace conventional concrete (CC) in many large-scale applications. UHPC has the ability to be cost-competitive on a first-cost basis while being far more valuable than the traditional CC on a long-term life cycle basis. By taking advantage of the key properties in UHPC, bridge and building members will become more efficient in the use of materials, while also being able to span farther. Lower consumption of construction materials will be good for the environment as it reduces carbon dioxide emission and global warming potential.

\section{Acknowledgement}

None.

\section{Conflict of Interest}

No conflict of interest. 